\title{
O GeoGebra 3D no Estudo de Projeções Ortogonais Amparado Pela Teoria das Situações Didáticas
}

\section{GeoGebra 3D in the Study of Orthogonal Projections Supported by the Theory of Didactic Situations}

\author{
Renata Teófilo de Sousa*a; Italândia Ferreira de Azevedo ${ }^{\text {a }}$ Francisco Régis Vieira Alves ${ }^{a}$ \\ anstituto Federal de Educação, Ciência e Tecnologia do Estado do Ceará, Campus Fortaleza. CE, Brasil. \\ *E-mail: rtsnaty@gmail.com
}

\begin{abstract}
Resumo
Este trabalho apresenta uma situação didática voltada para o estudo de projeções ortogonais, auxiliado pelo GeoGebra 3D, em sua versão de aplicativo para smartphone. Para este estudo foi utilizada como base conceitual a Teoria das Situações Didáticas (TSD). O objetivo deste trabalho é mostrar como a visualização de projeções ortogonais por meio da construção geométrica 3D auxilia na compreensão e no desenvolvimento da visão espacial do aluno. Para tal, apresentam-se os resultados de uma aplicação para o ensino de Geometria Espacial, desenvolvendo a relação entre a visão 2D e 3D dos alunos, orientada e elaborada com base nas dialéticas da TSD - ação, formulação, validação e institucionalização -, realizada de forma remota, devido ao cenário de pandemia em que o mundo se encontra. Para sua estruturação foi selecionada uma questão do Exame Nacional do Ensino Médio (ENEM) sobre o assunto de projeções ortogonais, trabalhada de forma dinâmica e interativa em um encontro virtual na plataforma Google Meet. A aplicação ocorreu com alunos de $3^{\circ}$ ano do Ensino Médio de uma escola pública estadual situada em Sobral - CE. Em síntese, aponta-se que a TSD associada ao GeoGebra 3D têm grande potencial para estimular a evolução do pensamento geométrico do aluno, atendendo o que se busca desenvolver nos currículos escolares.
\end{abstract}

Palavras-chave: Projeções Ortogonais. GeoGebra 3D. Teoria das Situações Didáticas.

\begin{abstract}
This work presents a didactic situation aimed at the study of orthogonal projections, aided by GeoGebra 3D, in its version of smartphone application. For this study, the Theory of Didactic Situations (TSD) was used as a conceptual basis. The objective of this work is to show how the visualization of orthogonal projections through the $3 D$ geometric construction helps in understanding and developing the student's spatial vision. To this end, the results of an application for the teaching of Spatial Geometry are presented, developing the relationship between the students' $2 D$ and $3 D$ vision, oriented and elaborated based on the dialectic of the TSD - action, formulation, validation and institutionalization - carried out remotely, due to the pandemic scenario in which the world finds itself. For its structuring, a question from the National High School Examination (ENEM) was selected on the subject of orthogonal projections, worked in a dynamic and interactive way in a virtual meeting on the Google Meet platform. The application occurred with 3rd year high school students from a state public school located in Sobral - CE. In summary, it is pointed out that the TSD associated with GeoGebra 3D has great potential to stimulate the evolution of the student's geometric thinking, attending to what is sought to develop in school curricula.
\end{abstract}

Keywords: Orthogonal projections. GeoGebra 3D. Theory of Didactic Situations.

\section{Introdução}

O Ensino e a Aprendizagem de Geometria são temáticas presentes em diversos estudos científicos no âmbito do Ensino de Matemática, em virtude de sua importância para o homem, desde a antiguidade. Conforme Lorenzato (1995, p.5) "sem conhecer Geometria a leitura interpretativa do mundo torna-se incompleta, a comunicação das ideias fica reduzida e a visão da Matemática torna-se distorcida".

A Geometria Euclidiana faz parte dos currículos escolares da educação básica brasileira e seus postulados servem como base para a Geometria Espacial, cerne deste trabalho. Deste modo, no que tange ao raciocínio geométrico, em visão bidimensional e tridimensional, é importante que o estudante desenvolva essa percepção por meio da visualização, estabelecendo relações entre o que se propõe nas situações matemáticas e na realidade, tendo a possibilidade de compreender formalmente o assunto, assim como sua aplicabilidade em diversas situações.

A importância do saber geométrico para o homem vem da necessidade de se perceber dentro do espaço. Contudo, mesmo com sua relevância comprovada, a Geometria como componente curricular da disciplina de Matemática é ainda um entrave para os estudantes (Camilo, Alves \& Fontenele, 2020). Em particular a Geometria Espacial, pois há uma dificuldade maior na percepção e associação dos entes geométricos fundamentais e sua respectiva associação à composição de figuras espaciais. Para Lorenzato (1995, p.3) "muitos professores não detêm os conhecimentos geométricos necessários para realização de suas práticas pedagógicas". O autor ainda afirma que esta lacuna é oriunda da formação 
docente, consequência do Movimento da Matemática Moderna, ocorrido nas décadas de 60 e 70, que minimizava a importância do Ensino de Geometria nas escolas.

Segundo Alves (2012) no que diz respeito ao contexto da resolução de problemas em Matemática, tratando-se do tipo de raciocínio mobilizado em busca de uma solução, identifica-se que o aluno pode desenvolver um raciocínio lógico-matemático formal ou, de outra maneira, mobilizar uma categoria de raciocínio que não possui características marcantes e determinantes de um raciocínio formal. Assim, falamos do raciocínio intuitivo, que contribui para a evolução do pensamento lógico formal, requerido em muitos problemas de Geometria e presente em avaliações e exames vestibulares, como o ENEM, por exemplo.

O Exame Nacional do Ensino Médio (ENEM) comumente utiliza questões de Geometria Espacial em seus testes para explorar potencialidades acerca do raciocínio geométrico dos estudantes. Devido sua aplicabilidade prática, é um assunto bastante recorrente em suas provas, sendo necessário seu desenvolvimento para que haja um bom desempenho nesta área do conhecimento. A Matriz de Referência do ENEM (Brasil, 2009), no que concerne à temática em questão, apresenta como competências e habilidades:

Competência de área 2 - Utilizar o conhecimento geométrico para realizar a leitura e a representação da realidade e agir sobre ela.

H6 - Interpretar a localização e a movimentação de pessoas/ objetos no espaço tridimensional e sua representação no espaço bidimensional.

H7 - Identificar características de figuras planas ou espaciais. H8 - Resolver situação-problema que envolva conhecimentos geométricos de espaço e forma.

H9 - Utilizar conhecimentos geométricos de espaço e forma na seleção de argumentos propostos como solução de problemas do cotidiano. (Brasil, 2009, p.5).

Esta Matriz traz a importância da associação do pensamento geométrico à realidade e reforça a questão da construção de modelos para a solução de problemas, o que muitas vezes não necessita de fórmulas ou expressões matemáticas prontas. Vale salientar que pelo caráter interdisciplinar do ENEM, seus enunciados costumam relacionar os conteúdos e as disciplinas dentro de suas competências e habilidades.

Assim, este trabalho tem como objetivo mostrar como a visualização de projeções ortogonais por meio da construção geométrica 3D auxilia na compreensão e no desenvolvimento da visão espacial do aluno. Para isto, utilizou-se uma situação didática embasada nesta matriz e organizada com base na Teoria das Situações Didáticas, com o aporte do GeoGebra enquanto recurso para a transposição didática, visando colaborar com o docente de Matemática, viabilizando a percepção visual e a compreensão de figuras espaciais por estudantes do Ensino Médio, abordando o tópico de projeções ortogonais.

A aplicação foi realizada de forma remota, via Google Meet, inicialmente com um grupo de 5 alunos do $3^{\circ}$ ano do Ensino Médio de uma escola pública de Sobral. O trabalho com um grupo reduzido de alunos ocorreu como forma de teste, para verificar a viabilidade de utilizar o aplicativo para celular durante aulas síncronas. A coleta de dados ocorreu por registro fotográfico, gravação de vídeo, transcrição de conversas no chat da plataforma e dois questionários (introdutório e avaliativo). Esta prática buscou dar ênfase no protagonismo do aluno para a construção de seu conhecimento, o que configura a TSD como teoria de ensino suporte aos objetivos elencados.

\section{Teoria das Situações Didáticas (TSD)}

A Teoria das Situações Didáticas (TSD) propõe uma maneira de entendermos a relação existente entre o trinômio aluno, professor e saber, bem como o meio (milieu) em que a situação didática ocorre, sendo esta chamada por Brousseau de Triângulo Didático, que tem seus vértices como representação das relações existentes entre esses três pilares.

Para que a aprendizagem do aluno ocorra, Brousseau (2008) traz que deve existir uma ligação entre o conhecimento e a interação entre duas ou mais pessoas, onde tais interações podem ocorrer pelo que ele chama de situação didática, que ocasiona a apreensão do conhecimento. Pode ser um jogo, um desafio ou qualquer tipo de dispositivo criado para que o aprendizado ocorra de forma efetiva. Assim, a situação didática é caracterizada por "um modelo de interação de um sujeito com um meio determinado" (Brousseau, 2008, p.20).

A situação didática, para funcionar de maneira efetiva, deve ser resguardada no que Brousseau traz como contrato didático. Brousseau (2008) define contrato didático como um contrato verbal que determina o papel dos sujeitos - professor e aluno -, lugares e funções de todos os envolvidos na situação didática, em um sistema de obrigações cuja reciprocidade é necessária, sendo essa relação mediada pelo saber.

Partindo desse ponto, a TSD traz como escopo aproximar o trabalho do aluno ao de um pesquisador, por meio da formulação de hipóteses, construção de conceitos, validação de estratégias e teorias, tendo o professor como mediador do processo, ao promover situações ou sequências didáticas previamente preparadas para que o aluno aja sobre o saber e o transforme em conhecimento para si mesmo. Para Brousseau (2008) as situações de ensino devem ser elaboradas pelo professor para que o aluno construa e se aproprie do conhecimento.

O processo de aprendizagem por meio da TSD é dividido em fases ou dialéticas que podem ser modeladas de acordo com as situações de ação, formulação, validação e institucionalização, possibilitando a aprendizagem do aluno. Deste modo, podemos sintetizar tais situações como:

Situação de ação: inicialmente, é a tomada de posição do aluno diante do problema proposto;

Situação de formulação: nesta fase, há uma troca de informações entre o aluno e o meio, juntamente à verbalização de ideias e conjecturas;

Situação de validação: o aluno apresenta sua estratégia de solução para a turma e tenta argumentar com base em seu 
raciocínio, verificando se o que ele conjecturou é, de fato, válido;

Situação de institucionalização: fase em que a figura do professor sintetiza tudo o que foi exposto nas etapas anteriores, de maneira formal e com linguagem matemática adequada.

Alves (2019) traz que as dialéticas apontadas acima demandam um expediente detalhado e cuidadoso de atenção e análise, na medida que temos o interesse da perspectiva e compreensão da ação do professor, mediada e apoiada em fundamentos que subsidiam e indicam a adoção de uma metodologia de ensino para Matemática.

O momento em que o estudante constrói o conhecimento ocorre na situação adidática, sendo ela, construída para que o aluno interaja com um ambiente sem a intervenção do professor, e esta situação compreende as três primeiras fases da TSD. Já a institucionalização, mostra-se como parte integrante da transformação do conhecimento - simples familiaridade, mas não intimidade com o objeto de estudo em saber - intelectual, que admite conceitos e juízos a respeito -, por meio do processo de devolução ${ }^{1}$, que ocorre ao longo de toda a situação didática.

A intenção de ensinar representa o processo de busca em transmitir o saber, ou seja, gerar conhecimento de uma situação (Margolinas, 2015). Desta forma, o processo de devolução no caso das situações adidáticas é considerado um processo mais geral, não vinculado de forma particular da organização do ensino. Por tais pressupostos, a TSD torna-se uma teoria de ensino que atende às necessidades deste trabalho.

\section{O GeoGebra como Recurso para a Transposição Didática}

A transposição didática permite a transformação do saber científico em saber escolar (Polidoro \& Stigar, 2010), possibilitando uma mediação entre esses conhecimentos para facilitar a compreensão do aluno. As diferentes formas como tais transformações podem ocorrer possibilitam um leque de possibilidades metodológicas ao professor. Chevallard (1991), nos traz a seguinte definição para transposição didática:

Um conteúdo de saber que tenha sido definido como saber a ensinar, sofre, a partir de então, um conjunto de transformações adaptativas que irão torná-lo apto a ocupar um lugar entre os objetos de ensino. O 'trabalho' que faz de um objeto de saber a ensinar, um objeto de ensino, é chamado de transposição didática. (Chevallard, 1991, p. 39, tradução nossa).

A busca por métodos que facilitem a compreensão e aprendizagem do aluno tem sido pauta de muitos trabalhos acadêmicos. A transposição didática por meio de tecnologias já vem sendo estudada por diversos autores, sendo alguns deles: Díaz-Urdanetta, Kalinke e Motta (2019), Abar (2020a) e Abar (2020b).

Díaz-Urdanetta, Kalinke e Motta (2019) reforçam que o
GeoGebra é uma ferramenta de matemática dinâmica e por sua acessibilidade e pouca complexidade em seu uso tornase um recurso que permite uma abordagem diferenciada, possibilitando a apresentação de vários tópicos de Matemática em uma única interface. Isto permite uma experimentação e visualização da Matemática com grande potencial para desenvolver o conhecimento do aluno.

Há um desafio grande para a escola atingir os objetivos da aprendizagem em Matemática. Apesar da evolução ao longo dos anos, ainda há um longo caminho a percorrer, principalmente no que diz respeito ao uso da tecnologia em sala de aula. O GeoGebra é um recurso que vem para agregar ao professor e facilitar sua prática, principalmente na apresentação de conteúdos de complexa assimilação, no entanto, muitos professores ainda têm dificuldades no manuseio desta ferramenta. Uma justificativa para isso, segundo Abar (2020a), é que para elaborar estratégias inovadoras por parte do professor exige uma dedicação maior ao seu desenvolvimento profissional, demandando mais tempo para que este consiga absorver todas as informações, estudar, analisar e transpor todas essas ideias para a sua prática.

Abar (2020a, p. 33) enfatiza que "o desenvolvimento das tecnologias da informação e comunicação, bem como sua introdução nas escolas e nos ambientes de formação, é acompanhando de fenômenos da mesma ordem que os da transposição didática". Ou seja, a compreensão do aluno é facilitada uma vez que o suporte tecnológico tem grande dinamismo, fornecendo subsídios para que a transposição didática ocorra de forma significativa.

Para que o recurso do GeoGebra proporcione uma aprendizagem efetiva, sugere-se que o docente esteja ciente da melhor forma de realizar a transposição didática do conteúdo associado a este recurso. Assim, "é importante a compreensão do complexo processo de transformação pelo qual passa a matemática até tornar-se um elemento a ser ensinado" (Abar, 2020b, p. 2).

Para tentar explorar essas teorias (TSD e Transposição Didática) dentro da proposta didática e elaboração da situação didática, a seção seguinte apresenta uma aplicação sobre o assunto de projeções ortogonais, seguindo os pressupostos supracitados.

\section{Aplicação da TSD para o Ensino de Projeções Ortogonais}

Para a organização da situação de ensino por meio da questão proposta, iniciamos o momento com um questionário introdutório, como sondagem do grupo, buscando saber quais seus conhecimentos prévios sobre o assunto que seria proposto, bem como sobre o uso do GeoGebra. Em seguida, empregamos o aplicativo GeoGebra $3 \mathrm{D}^{2}$ para smartphones,

1 Brousseau (2008, p. 89) traz que "a devolução é o ato pelo qual o professor faz com que o aluno aceite a responsabilidade de uma situação de aprendizagem (adidática) ou de um problema e assume ele mesmo as consequências dessa transferência".

2 O aplicativo é "Calculadora gráfica GeoGebra 3D" na Play Store, para sistema Android, disponível em https://play.google.com/store/apps/ details?id=org.geogebra.android.g3d e com o nome "Calculadora GeoGebra 3D" na App Store, para sistema iOS, disponível em https://apps.apple. com/br/app/calculadora-geogebra-3d/id1445871976. 
no amparo à visualização e estruturação do pensamento geométrico acerca de projeções ortogonais. Segundo Alves e Borges Neto (2012) a exploração do GeoGebra como instrumento tecnológico possibilita a visualização de situações inimagináveis, quando restritas ao lápis e papel.

Complementando o pensamento de Alves e Borges Neto (2012), temos Souza, Galvão e Souza (2014), que reforçam a importância de deixar explícitas as regras para construção de representações bidimensionais relativas à figuras tridimensionais, para que os alunos compreendam e usem estas figuras de modo a codificar e decodificar situações de forma correta, com base nessas representações.

Para esta aplicação utilizamos uma questão extraída do ENEM (Figura 1), seguindo o processo de aprendizagem a partir da TSD, sendo modeladas pelas situações de ação, formulação, validação e institucionalização.

Figura 1 - Questão do ENEM sobre projeção ortogonal

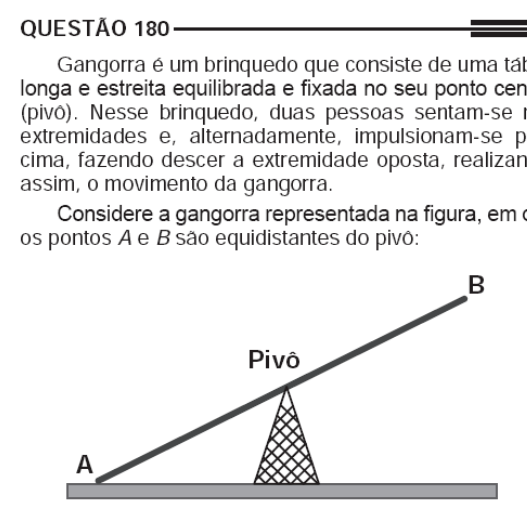

A projeçáo ortogonal da trajetória dos pontos $A$ e $B$, sobre o plano do chao da gangorra, quando esta se encontra em movimento, é:

Fonte: Prova do Enem 2013, segundo dia, questão 180, prova azul.

O objetivo do problema é identificar qual das alternativas apresentadas na questão representa a projeção ortogonal da gangorra, o que faria com que o aluno buscasse visualizála de cima para baixo, identificando geometricamente a posição correta. A partir do contrato didático firmado entre o professor e o grupo, foi acordado que os alunos realizariam uma construção no aplicativo GeoGebra, executando-a passo a passo com o professor.

A referida construção serviu de suporte à compreensão da situação didática proposta. Na Figura 2 temos a construção apresentada na interface do aplicativo GeoGebra 3D para smartphone e, como comparativo, na Figura 3 apresentase a visualização desta mesma construção na interface no software GeoGebra, para computadores. Observe que há algumas diferenças na disposição dos comandos dentro de cada interface.
Figura 2 - Visualização da construção geométrica no app GeoGebra 3D, na interface do aplicativo de celular

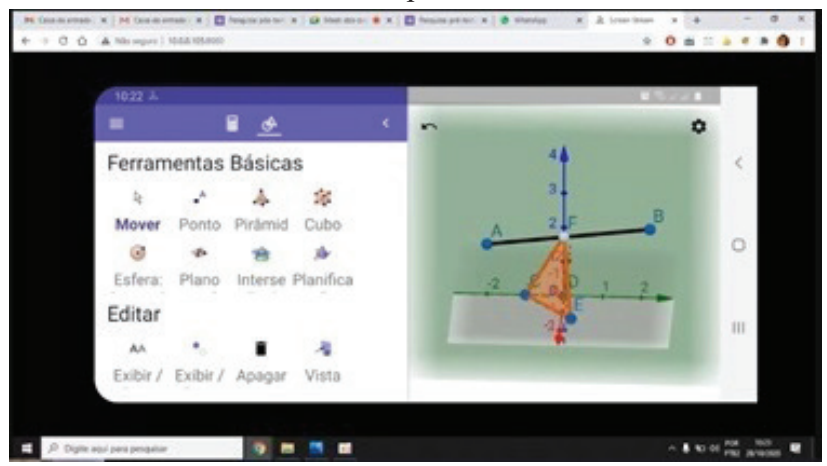

Fonte: Os autores.

Figura 3 - Visualização da construção geométrica no app GeoGebra 3D, na interface do software no computador

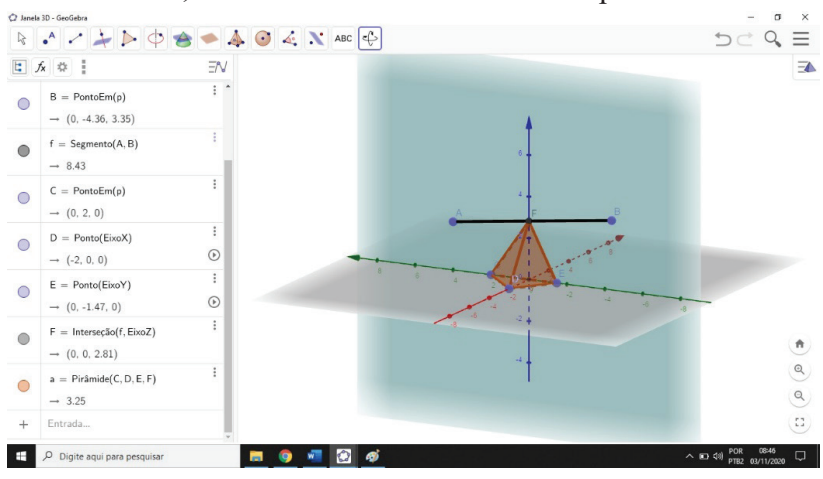

Fonte: Os autores.

Após a construção inicial, os alunos foram incentivados a rotacionar a figura e analisá-la de diversos ângulos utilizando o aplicativo. Observe que, nas Figuras 2 e 3, o professor está projetando a tela de um smartphone e apresentando a construção em um aplicativo, para que os estudantes tenham a visualização da mesma interface, tendo em vista que o layout da janela 3D do GeoGebra para computadores oferece uma visão diferente dos smartphones, com relação à disposição das ferramentas. Após a construção, a questão citada foi apresentada aos alunos.

Como ação inicial, os alunos fizeram uma leitura atenta da situação proposta e foram instigados pelo professor mediador com a seguinte indagação: Quais conteúdos matemáticos vocês conseguem perceber dentro desta questão? As respostas foram: Geometria Espacial, segmento de reta, semelhança de triângulos e circunferência. O grupo seguiu buscando relacionar os dados apresentados a uma solução coerente. A partir deste ponto, percebemos o início da situação de formulação, como explanada anteriormente.

Nesta fase, o grupo foi instigado a rotacionar novamente a figura no GeoGebra e fizeram algumas observações, de forma coletiva. A intenção era que eles percebessem que a visão superior da figura poderia fazê-los chegar a conjecturas sobre a solução da questão. Nas Figuras 4 e 5 apresentam-se registros dessa manipulação. 
Figura 4 - Aluno A manipulando a construção

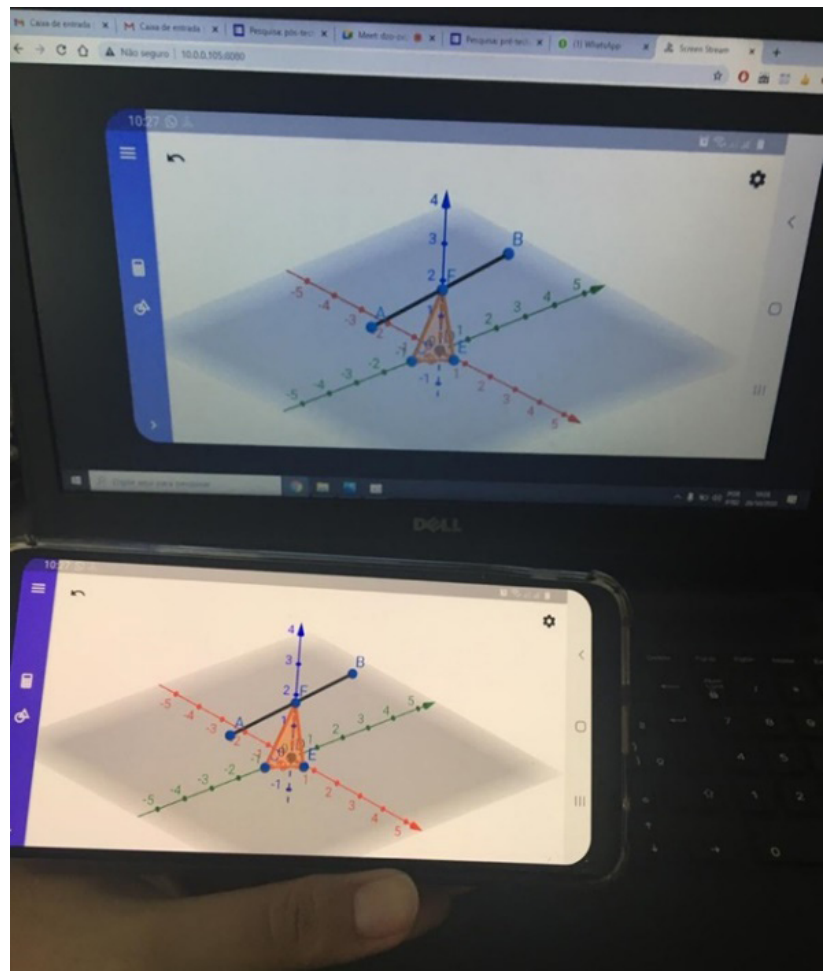

Fonte: Os alunos.

Figura 5 - Aluno B manipulando a construção

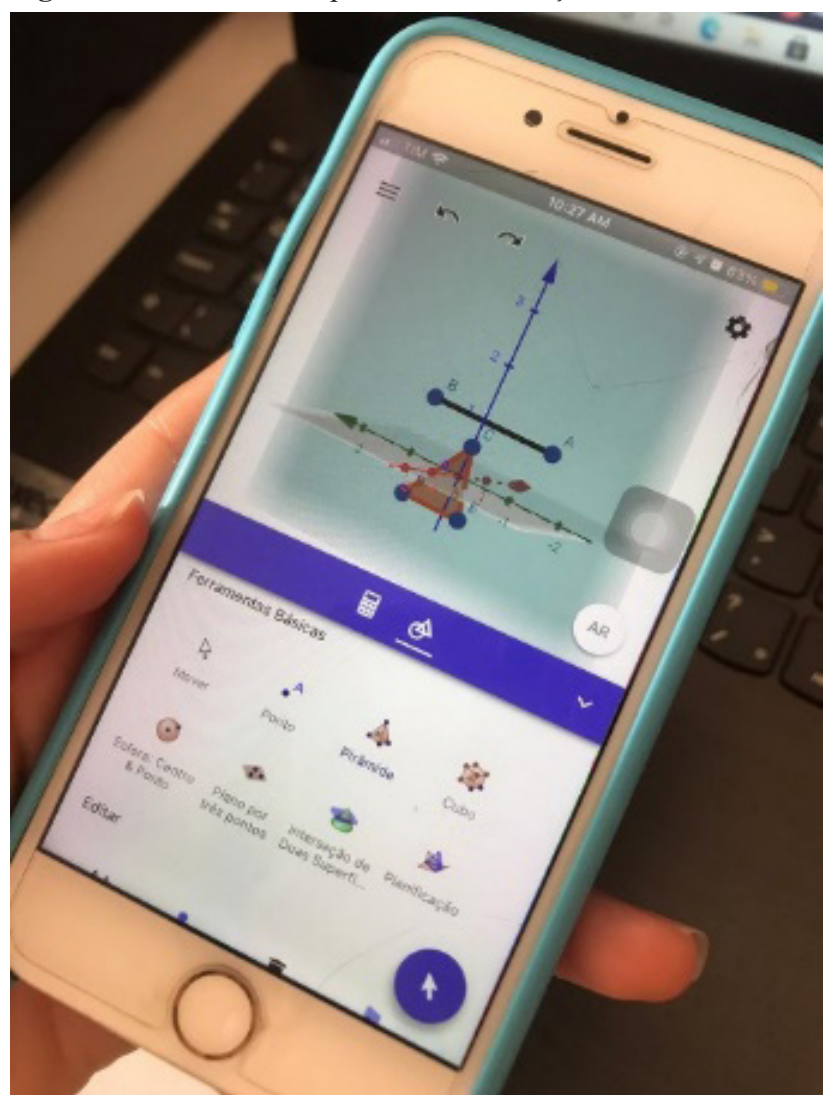

Fonte: Os alunos.

Pode-se observar nas Figuras 4 e 5 que os integrantes, além de rotacionarem a construção, também buscaram modificar o vértice do pivô de seu local, o que reforça o quanto o GeoGebra 3D foi importante para permitir uma visualização tridimensional, oportunizando experimentar e construir conceitos geométricos.

Após manipulação da construção e diálogo entre os pares, observamos o início da validação, em que um dos integrantes do grupo apresentou como solução a letra B, que constava duas retas horizontais, enquanto outro integrante apontou a letra $C$, que trazia duas curvas como resposta. Houve argumentação e contra-argumentação dos envolvidos, chegando à conclusão de que o item $\mathrm{C}$ apresentado é referente à visão frontal do balanço, enquanto o item B é a visão superior. Após consenso, assinalaram o item B como alternativa correta. Na Figura 6, temos a ilustração da projeção ortogonal da situação didática proposta, sendo a solução do problema.

Figura 6 - Projeção ortogonal do balanço

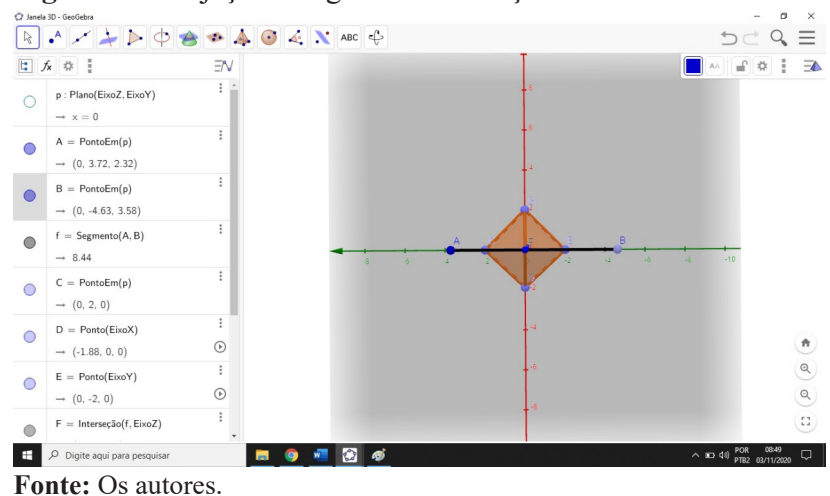

Nesta etapa final da situação didática proposta, o professor levou em consideração todas as observações geradas pelos alunos para sintetizar as ideias apontadas e comparou o modelo construído no GeoGebra e a proposta da questão apresentada, realizando a institucionalização sobre o assunto. $\mathrm{O}$ intuito desta questão era levar o estudante a perceber uma aplicação do conceito de projeção ortogonal, dentro da Geometria. Assim, o professor apresentou o conceito de projeção ortogonal, utilizando a página da internet Brasil Escola, que trouxe:

Dada uma figura geométrica qualquer e um plano que não contém nenhum de seus pontos, a projeção ortogonal dessa figura sobre o plano é a imagem formada no plano pelo pé do segmento de reta ortogonal a esse plano que liga cada ponto dessa figura ao plano. Uma projeção ortogonal, portanto, pode ser imaginada como a sombra de uma figura geométrica em um plano sob o sol do meio-dia. (Silva, 2020).

Alguns do grupo desconheciam o conceito de projeção ortogonal, mas relacionaram de maneira simplista à metáfora "sombra" em um horário de sol à pino, antes mesmo da apresentação em linguagem matemática.

A questão apresentada explora o assunto de projeções ortogonais, induzindo o aluno à compreensão da Geometria a partir de uma exploração visual. Segundo Lorenzato (1995) é comum os alunos não terem reação ao se deparar com este tipo de questão, pois não foram dados números ou medidas, o que denota a forte tendência de aritmetização do raciocínio, por 
meio de fórmulas prontas, tornando o aprendizado mecânico. Em algumas situações são necessárias, apenas, uma percepção geométrica, raciocínio geométrico e linguagem geométrica para solucioná-las.

\section{Resultados da Aplicação}

Antes do início da aplicação foi solicitado ao grupo de alunos participantes que respondessem a um questionário inicial, para sondagem acerca da utilização do GeoGebra enquanto recurso escolhido. Este questionário contou com quatro perguntas objetivas que foram: Você já conhece o GeoGebra? Você alguma vez utilizou o GeoGebra durante as aulas? Você tem dificuldades para fazer desenhos geométricos? Você gostaria de estudar Geometria de uma forma mais dinâmica?

De acordo com a coleta das respostas obtivemos que: Todos os alunos conheciam o GeoGebra; dentre o grupo de cinco alunos, dois deles nunca haviam utilizado o GeoGebra em aulas; todos os alunos responderam que têm dificuldades em fazer desenhos geométricos e; todos os alunos afirmaram ter interesse em estudar a Geometria de forma mais dinâmica.

Durante a aplicação foram coletadas algumas falas dos alunos, apresentando seus conhecimentos prévios e suas ideias para a resolução do problema, bem como registros fotográficos de suas construções no aplicativo, como descrito na seção anterior.

Por fim, após a aula, solicitou-se que os alunos respondessem um segundo questionário sobre a avaliação da aula, trazendo suas reflexões sobre o uso do aplicativo como suporte para a visualização e solução desta questão e a experiência vivenciada.

A primeira pergunta do questionário foi "Qual a sua reação ao construir a gangorra no GeoGebra?”. Quatro alunos afirmaram achar interessante pela visualização, dinamismo e o fato de ser uma metodologia diferente, enquanto um aluno afirmou achar muito difícil realizar a construção no GeoGebra $3 \mathrm{D}$.

Na segunda pergunta indaga-se "A construção no GeoGebra ajudou na compreensão/visualização do problema?”. A resposta foi unânime: todos concordaram que sim.

$\mathrm{Na}$ terceira pergunta foi solicitado que cada aluno escrevesse um feedback sobre a aula com a manipulação do aplicativo. O compilado destas respostas foi:

Aluno A: De acordo com a o movimento da gangorra, olhando na parte superior, tem - se o segmento horizontal no plano do chão, como está destacado na opção B. A percepção da questão mudou. Se eu não tivesse feito no GeoGebra e sim no papel, com certeza minha ideia seria diferente ou eu não conseguiria resolver a questão.

Aluno B: A gente pode ter uma visão geral da posição da gangorra. Uma aula muito interessante, pois a partir de cada problema, o GeoGebra veio com uma maneira de solucionar de maneira mais fácil o problema.

Aluno C: Achei bem dinâmica e ajudou a entender facilmente o problema. Muito cativante, deveríamos usar mais vezes.

Aluno D: É bastante interessante, pois a visualização ajuda de forma expressiva na compreensão da problemática. Achei bem bacana, apesar de um pouco complexo, mas acredito que ao longo das práticas, fica ótimo. É realmente uma forma bem lúdica e diferente de estudar geometria.

Aluno E: Foi bacana essa aula para o descobrimento das ferramentas do GeoGebra. Eu tenho duas respostas para a questão, uma que foi difícil, mas que ao mesmo tempo foi interessante. Tive dificuldade de construir a pirâmide no primeiro momento, mas depois que entendi como funcionava foi fácil.

Partindo dos depoimentos dos alunos, todos concordaram que o GeoGebra contribuiu para a visualização e percepção geométrica, sugerindo que este recurso deveria ser mais explorado em aulas de Matemática. Com ênfase no depoimento do Aluno A, percebe-se que a Transposição Didática com o auxílio do GeoGebra ocorreu de forma efetiva. Corroborando a este pensamento, Abar (2020a, p. 62) traz que "Tornar um conceito mais compreensível vem ao encontro do apoio das tecnologias digitais que, com o dinamismo inerente a algumas delas, permite a transformação de um objeto matemático facilitando seu aprendizado".

\section{Considerações Finais}

Com este trabalho concluímos que a TSD pode contribuir significativamente para a elaboração de aulas que proporcionem a participação ativa do aluno na construção do seu conhecimento. Considerando a relevância do uso de tecnologias para o ensino de projeções ortogonais, a TSD associada ao GeoGebra 3D possibilitou a construção de uma situação didática com potencial para desenvolver a percepção geométrica dos alunos.

A partir desta aplicação, percebemos que a TSD possibilitou a autonomia do aluno, que passou a comportar-se como investigador, buscando solucionar a questão por meio de seus conhecimentos matemáticos. Além disso, foi uma experiência positiva para a práxis do professor, que com a mediação da situação didática aplicada, teve oportunidade de aprimorar sua metodologia com o uso de tecnologias em sala de aula.

No que concerne ao uso do GeoGebra 3D, os depoimentos dos alunos conferem legitimidade no que diz respeito à sua contribuição para o desenvolvimento da percepção geométrica por meio da visualização tridimensional. Logo, este aplicativo configura-se em um recurso que pode ser difundido nas escolas como contributo ao ensino, não apenas de projeções ortogonais, mas de muitos outros temas relacionados à disciplina de Matemática.

\section{Referências}

Abar, C.A.A.P. (2020). A Transposição Didática na criação de estratégias para a utilização do GeoGebra. Revista do Instituto GeoGebra de São Paulo, 9(1), 59-75, doi: https:// doi.org/10.23925/2237-9657.2020.v9i1p59-75.

Abar, C.A.A.P. (2020). Teorias da Transposição Didática e Informática na criação de estratégias para a prática do professor com a utilização de tecnologias digitais. Revista 
Sergipana de Matemática e Educação Matemática, 5(1), 2945, doi: https://doi.org/10.34179/revisem.v5i1.11893.

Alves, F.R.V. (2019). Visualizing the Olympic Didactic Situation (ODS): teaching mathematics with support of the GeoGebra software. Acta Didactica Napocensia, 12(2), 97-116, doi: 10.24193/adn.12.2.8.

Alves, F.R.V. (2012). Insight: descrição e possibilidades de seu uso no ensino do cálculo. Vidya, 32(2), 149-161, doi: https:// doi.org/10.37781/vidya.v32i2.279.

Alves, F.R.V., \& Borges Neto, H. (2012). Engenharia Didática para a exploração didática da tecnologia no ensino no caso da regra de L'Hôpital. Educação Matemática Pesquisa, 14(2), 337 - 367, doi: https://revistas.pucsp.br/index.php/emp/ article/view/9445/8147.

Brasil. (2009). Instituto Nacional de Estudos e Pesquisas Educacionais Anísio Teixeira (INEP). Matriz de referência para o ENEM.

Brousseau, G. (2008). Introdução ao estudo das situações didáticas: conteúdos e métodos de ensino. São Paulo: Ática.

Chevallard, Y. (1991). La transposition didactique: du savoir savant au savoir enseigné. Paris: Ed. La pensée Sauvage.

Camilo, A.M.S., Alves, F.R.V., \& Fontenele, F.C.F. (2020). A Engenharia Didática articulada à Teoria das Situações Didáticas para o ensino da Geometria Espacial. Revista
Iberoamericana de Educación Matemática, 16(59), 6482, doi: https://union.fespm.es/index.php/UNION/article/ view/127.

Lorenzato, S.A. (1995). Por que não ensinar Geometria? In: A Educação Matemática em Revista. Blumenau: Sociedade Brasileira de Educação Matemática, 4(3), 3-13.

Margolinas, C. (2015). Situations, savoirs et connaissances: omme lieux de rencontre? Formation et pratiques d'enseignement en questions, 2(19), 31-39, doi: http://revuedeshep.ch/ pdf/19/2015-Margolinas-FPEQ-19.pdf.

Polidoro, L.F. \& Stigar, R. (2010). A Transposição Didática: a passagem do saber científico para o saber escolar. Ciberteologia - Revista de Teologia \& Cultura, São Paulo, 27, 153-159, doi: https:/ciberteologia.com.br/images/edicoes/ pdf/edicao_20200709200438.pdf.

Silva, L.P.M. (2020). Projeções ortogonais. Brasil Escola (online). Recuperado em 31 de outubro de 2020 de: https:// brasilescola.uol.com.br/matematica/projecoes-ortogonais. htm.

Souza, V.H.G., Galvão, M.E. E.L. \& Souza, W.R.S. (2014). Representações bidimensionais de figuras tridimensionais: um estudo com a visualização. Jornal Internacional de Estudos em Educação Matemática, 7(1), 87-109, doi: https:// doi.org/10.17921/2176-5634.2014v7n1p\%25p. 